\title{
Multiplatform Application Technology - Based Heutagogy on Learning Batik: A Curriculum Development Framework
}

Isma Widiaty*, Ana, Lala Septem Riza, Ade Gafar Abdullah, Sugeng Rifqi Mubaroq

Universitas Pendidikan Indonesia, Bandung, Indonesia

*Correspondence: E-mail: isma@upi.edu

\begin{abstract}
A B S TR A C T
This study aimed to design a batik learning medium for vocational high school students in based on multiplatform. The application made was expected to support heutagogy approach - based learning and to deal with the development of science and technology integrated in the curriculum of vocational high schools. The application developed, namely e-botik, was an integration of several previously-designed applications using Code ignitor $(\mathrm{Cl})$ framework. The database used was My-SQL. It is commonly known that Code igniter is an open source web application framework utilized to create dynamic PHP applications. In this study, e-botik consisted of three main components including interface, database, and application programming interface (API). Some of the applications combined were ARtikon_joyful (Android-based), Video Kasumedangan Batik (movie player), Nalungtik Batik (desktop-based), Digi_Learnik (web-based), Batik UPI (manual), Batik Cireundeu (manual), and Lembar Balik (manual). The combination proceeded web-based so that it was compatible with various operating systems. The application (e-botik) was designed and then tested. The test was performed through whitebox testing and blackbox testing. The results of the test showed that it ran well and was able to be used a batik learning media. It is expected that students can utilize e-botik in selecting topics of learning batik in accordance with their competences and needs. This condition enables e-botik to support learning batik through heutagogical approach. In addition, the application was also validated in terms of both system and usage aspects.
\end{abstract}

\begin{tabular}{l} 
A R T I C L E I N F O \\
\hline Article History: \\
Submitted/Revised 05 Jul 2019 \\
First revised 29 Oct 2019 \\
Accepted 27 Jan 2020 \\
First available online 28 Jan 2020 \\
Publication date 01 Mar 2020 \\
\hline Keywords: \\
Curriculum Development, \\
Heutagogy, \\
Multiplatform Learning, \\
Learning, \\
Self-Determined Learning
\end{tabular}




\section{INTRODUCTION}

Heutagogy is a new paradigm in education emphasizing student leadership aspects. Some of the special features of heutagogical approach are self-efficacy, knowing how to learn, creativity, and giving students an ability to be able to implement their competences flexibly in a variety of situations (Hase \& Kenyon, 2003; Abraham \& Komattil, 2017). Fundamentally, heutagogical approach represents life-long learners model (Blaschke, 2012; Green \& Schlairet, 2017), where students learn for a lifetime. This ability is the primary capital for them to have competences in accordance with the development and to deal with the present and future problems by learning from experiences. The approach, when used in learning, is most likely to trigger students' self-awareness so they can learn optimally. Heutagogy is also a learning concept transforming learning content to learning to learn (Narayan \& Herrington, 2014). It leads students to have the experience of learning by doing and find their most effective way of learning (Blaschke, 2014).

Heutagogical approach is becoming a new alternative in improving the quality of learning within the rapid growth and development of information technology. It is a learning approach utilizing the most recent technology which is identical with digital teaching and learning (Blaschke, 2012). Learning using this approach is commonly dominated with the use of internet or the so-called "net centric" (Canning \& Callan, 2010) with various online platforms. The approach is believed to be an alternative of learning model which is able to motivate students to learn more enthusiastically due to the ease they acquire from the use of the internet. This way, students can effectively implement their skills and competences to face the global challenges both in the present time and the future.
One of the facilities of information technology is the availability of a learning alternative in a multiplatform. This facility offers interesting learning, multiple choices of learning resources, and freedom to students to organize their learning independently (Rieger \& Majchrzak, 2019). These characteristics of multiplatform-based learning match those of learning batik. Learning batik basically discusses the values of local wisdom of a particular area in Indonesia represented by batik patterns produced. Learning batik, especially for the youth, is important in order to preserve the noble values of batik and to be a part of Indonesia's identity. However, learning batik is often considered old school considering it has everything to do with the previous generation. One of the efforts to deal with this is by developing learning media interesting for the young generation; one of which is by utilizing the technology. Separately, in different platforms, we have developed a variety of desktop-based batik learning media as an alternative of batik information system development in a certain area (Widiaty et al., 2018) such as an Android-based batik learning medium using Augmented Reality application (Widiaty et al., 2017; Widiaty et al., 2018) and webbased batik learning media (Widiaty et al., 2018; Widiaty et al., 2018). However, those platforms can actually be integrated within a learning medium according to the principles of heutagogical learning which is multiplatform learning.

This paper aims to design batik learning media in the setting of multiplatform by integrating a variety of digital media previously made based on desktop, android, and web. The development is expected to provide a learning medium alternative coping with the future curriculum involving digital technology. The developed media are also in accordance with heutagogical 
approach, a new approach in learning enabling students to learn with plenty of learning resources. The multiplatform media are also able to train students to have selfindependence in learning, particularly in organizing their learning based on their needs.

\section{THEORETICAL FRAMEWORK}

\subsection{Technology integration in vocational high school curriculum}

Nowadays, the use of technology in education is inevitable. Information technology - based learning is a part of digital learning. There are several advatanges of integrating technology into learning; some of which are making learning, including batik learning, more innovative (Forsström, 2019), promoting students' critical thinking (Ataie et al., 2018), and creating more meaningful curriculum (Schüler, 2019).

Integrating technology into learning implies the need of a special approach with high level of effectiveness and efficiency in order to reach learning objectives. One of the applicable approaches is TPACK which stands for Technological, Pedagogical, \& Content Knowledge which focuses on technological aspects in a pedagogical context (Forsström, 2019). It is also known not service learning pedagogy is a technology-integrating approach in learning with such stages as administration and management, planning, implementation, reflection, and assessments (Salam et al., 2019).

Another factor in need of serious attention in the process of technology integration in learning are the roles and competences of teachers, particularly in the aspect of digital technology tool mastery (Forsström, 2019). In addition, facilities are also an important element in technology integration in learning since it has everything to do with access, infrastructure, and digital learning environemtn (Salam et al., 2019). In the level of management, leadership at schools is also an impotant factor influencing the success of learning with technology integration (Van Thiel, 2018).

\subsection{Heutagogy in the perspective of curriculum development}

Heutagogy shares the same spirit and basic ideas with curriculum development as they both prepare to face the future by adjusting to the current development of technology (Blaschke, 2012). In this context, curriculum needs to be able to give students future skills in the context of present perplexing world (Abraham \& Komattil, 2017; Law, 2014). The approach is also expected to be able to be a moving curriculum between competencies owned by the students as their learning output and skills needed in the industry (Hase, 2012). It has been proven that the approach leads teachers to develop a curriculum in the context of students' needs (Paik, 2015). This is due to the fact that the approach requires a living curriculum playing a role of key driver in learning (Hase \& Kenyon, 2007) where students have concrete, flexible, and open-minded learning based on their perspectives.

Students' needs in learning are the main focus of heutagogy approach. Students can create their own learning mapping and communicate the topics they are eager to learn. In this context, the approach refers to the principles of negotiated curriculum and gives students a chance to design their own curriculum (Narayan \& Herrington, 2014; Hase \& Kenyon, 2003; Hyun, 2006). An effort to involve students in curriculum development based on their capacity tends to have a positive impact where students are able to perform "seeing and understanding" processes towards what they learn. Some of the activities students can involve in curriculum development are clarification, challenge, and redefinition (Brooman et al., 2015). 
It is known that heutagogy implements the principles of flexible curriculum (Blaschke, 2012) and flexible learning (Hase \& Kenyon, 2001a). In addition, it applies the principles of transformative curriculum, where students are able to implement what they learn in their work fields accommodatively (Halsall et al., 2016). In the process of curriculum development, heutagogy can be facilitated by various learning approaches (Abraham \& Komattil, 2017). The approach does not only discuss competences but also capability and ability issues so that it is oriented to outcomebased curriculum where the learning impacts are capable learners (Abraham \& Komattil, 2017).

\subsection{Heutagogy and self-determined learning}

Heutagogy is also well-known as selfdetermined learning (Blaschke, 2014) where students provide various learning resources so that students can select what is best for them autodidactly (Haworth, 2016; Blaschke, 2012). Therefore, students have full freedom to determine what and how to learn. This concept is in line with heutagogy (Hase \& Kenyon, 2001b; Abraham \& Komattil, 2017), in which students are self-determined. It is even considered a magical way to pursue the objective of the curriculum (Hase, 2011).

Heutagogy is a learning system designed to be relevant to flipped classroom (Green \& Schlairet, 2017) since flipped classroom basically shares the same ideas as selfdetermined learning where students evaluate the whole learning processes back and forth. In addition, students are also able to control their own learning implementing the theory of spiral reflection (Canning \& Callan, 2010).

Heutagogy is a new approach attempting to give values to the previous approaches known as pedagogy and andragogy. Results of several studies revealed that heutagogy gave students more chances to acquire expertise useful for their future works within the society. In general, it can be concluded that pedagogy focuses on engagement and andragogy focuses on cultivation. In the meantime, heutagogy focuses more on realization (Blaschke, 2012).

\subsection{Heutagogy and multiplatform learning}

Heutagogy implies multiplatform learning; some of which are learning using social media and distant learning. Heutagogy is also equipped with learning tools varying from mobile learning to other media. Some of social media applicable to heutagogical learning are google docs, mind mapping, and e-portfolio software (Blaschke, 2014). Multiplatform learning is also a type of learning accessible through such devices as desktops, tablets, tough interaction, and smartphones (Sangiorgi, 2014; Rodriguez-Gil et al., 2017; Pereira et al., 2017). In addition, it is also accessible through the use of mobile and web technology (Adinugroho et al., 2015).

\subsection{Learning batik at vocational high schools}

Batik is one of the arts and cultural heritage of Indonesia. It is even officially acknowledged by the UNESCO as the world heritage. Thus, batik is a valuable cultural asset which needs to be preserved. One of the effective ways to preserve batik is by introducing it to the young generation through formal education (Widiaty et al., 2018). In Indonesia, several vocational high schools have textile craft majors promoting batik learning. This mainly aims to give students adequate knowledge and skills of making batik within a three-year learning period.

Learning batik is basically learning Indonesian culture. It is also closely related to learning Indonesian local wisdom represented in the batik patterns and batik making procedure. It is confirmed that each batik pattern has their own meanings and messages related to arts, culture, flora, fauna, nature, 
belief, and even a certain iconic area (Widiaty et al., 2017). This makes learning batik strategic for the youth, particularly in integrating the local wisdom and preserving the nation' identities.

\section{MATERIALS AND METHODS}

The research employed Research and Development (R\&D) method with waterfall application development procedure consisting of five steps such as communication, design, modeling, construction, and distribution. The application, namely e-botik, was developed by integrating several previously developed applications. Those applications came with different platforms; Android-based, desktopbased, and web-based. They were also applicable in different operating systems (see Figure 1). Some of the integrated applications were Artikon_Joyful (Android-based), Video Kasumedangan Batik (movie player), Nalungtik Batik (desktop-based), Digi_Learnik (webbased), Batik UPI (manual), Batik Cireundeu (manual), and Lembar Balik (manual). The application integration process was web-based, which makes it compatible with various operating systems. The application integration also creates application programming interface (API) web.

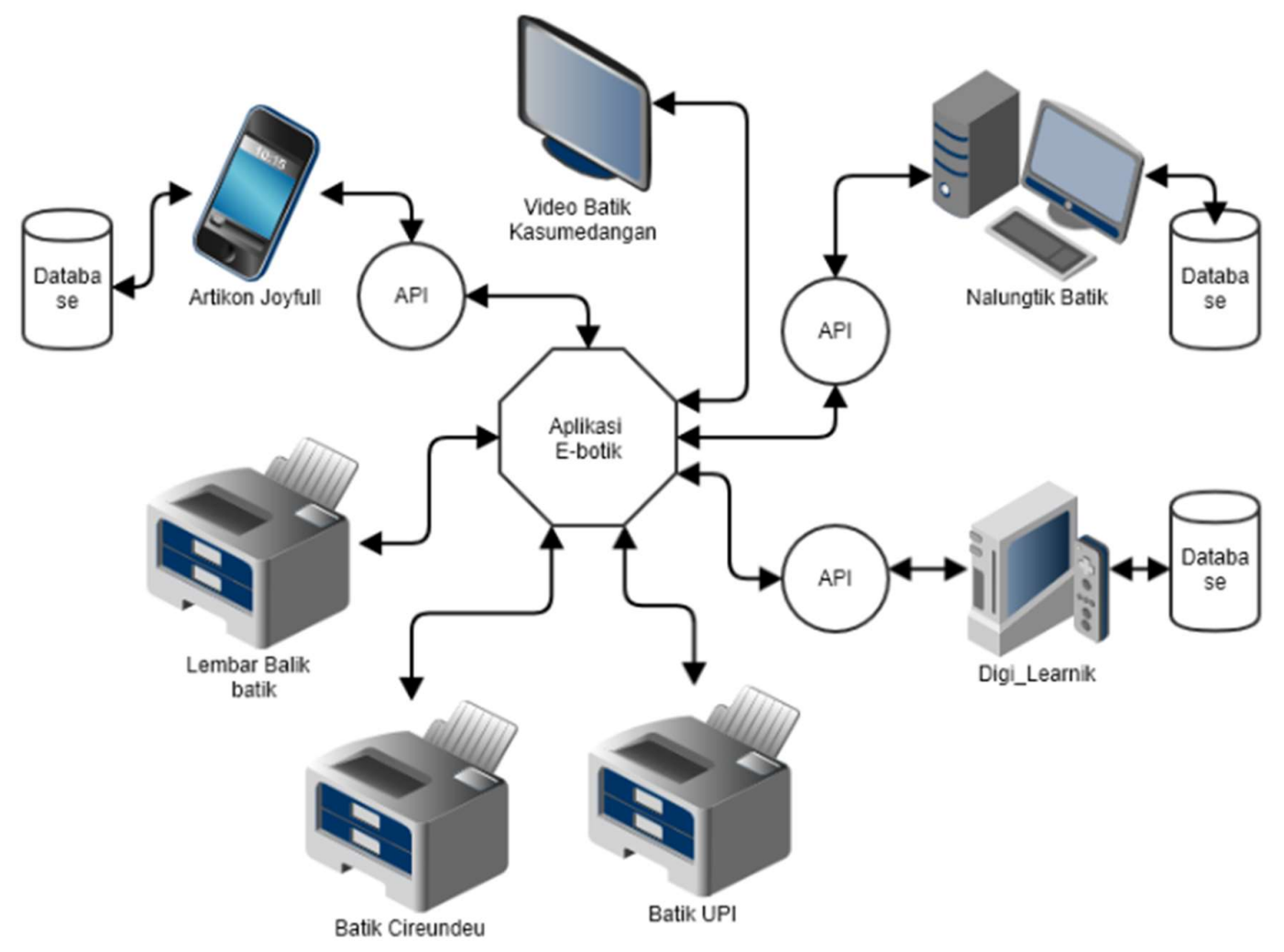

Figure 1. Ilustration of $\mathrm{Cu}$-ETA complex

\section{RESULTS AND DISCUSSION}

\subsection{Application development}

It has been discussed earlier that the application integration creates API web which has a bunch of instructions, functions, and protocols used by programmers when creating a software (Chow et al., 2011). An API web is like an end point made to deal with several relevant tasks with parameters as necessary data to display what is desired (Donovan \& edition, 1972; Guccione et al., 1999). It also functions as a connector of each previous application synchronized on e-botik. 
E-botik application consisted of three main components including user interface, database, and API. It was developed using code ignitor (Cl) framework and My-SQL database. It is commonly known that code igniter is an open source web application framework used to build a dynamic PHP application. Its main purpose was to help developers accelerate their works so they do not have to write their coding from the beginning (Hustinawati et al., 2014).

Code Igniter is flexible and light so that it is applicable to ease up learning, modify, and integrate Library and Helper (Gani, 2018). It uses MVC patterns so that the codes created are more structured and clearly standardized. In addition, it also results in a friendly URL. How code igniter works is shown in Figure 2. It starts with the browser which will interact through the controller. The controller will then receive and reply every request from the browser. For the data, the controller will ask the model, and for the UI, it will ask to see it. When the browser requires the web page, the router will make the controller deal with it. The controller will then be used to access the data and model display to display the data (Prokofyeva \& Boltunova, 2017).

MVC was used to separate data and logic access from the data presentation and user interaction. The separation was carried out so that the logic changes would not give each other complex effects. This separation solution was expected to increase the application flexibility and usability (Vuksanovic \& Sudarevic, 2011).

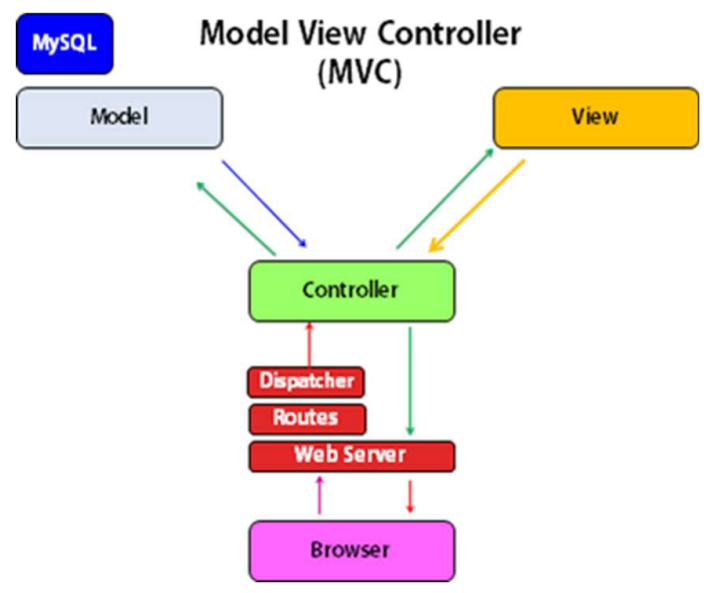

Figure 2. Structural work of code igniter (Hustinawati et al., 2014)

\subsection{User interface}

The design of the application user interface is shown in Figure 3. It contains three main displays covering initial display showing guidance and about application, login form, and register new user. The process of source code user interface design is presented in Figure 4. The next display is where users choose the menu. The last display is the batik learning media with various menus. Some of them present videos, batik database, pictures of batik patterns, and other explanations. The sample displays are shown in Figure 5. 
51 | Indonesian Journal of Science \& Technology, Volume 5 Issue 1, January 2020 Hal 45-61

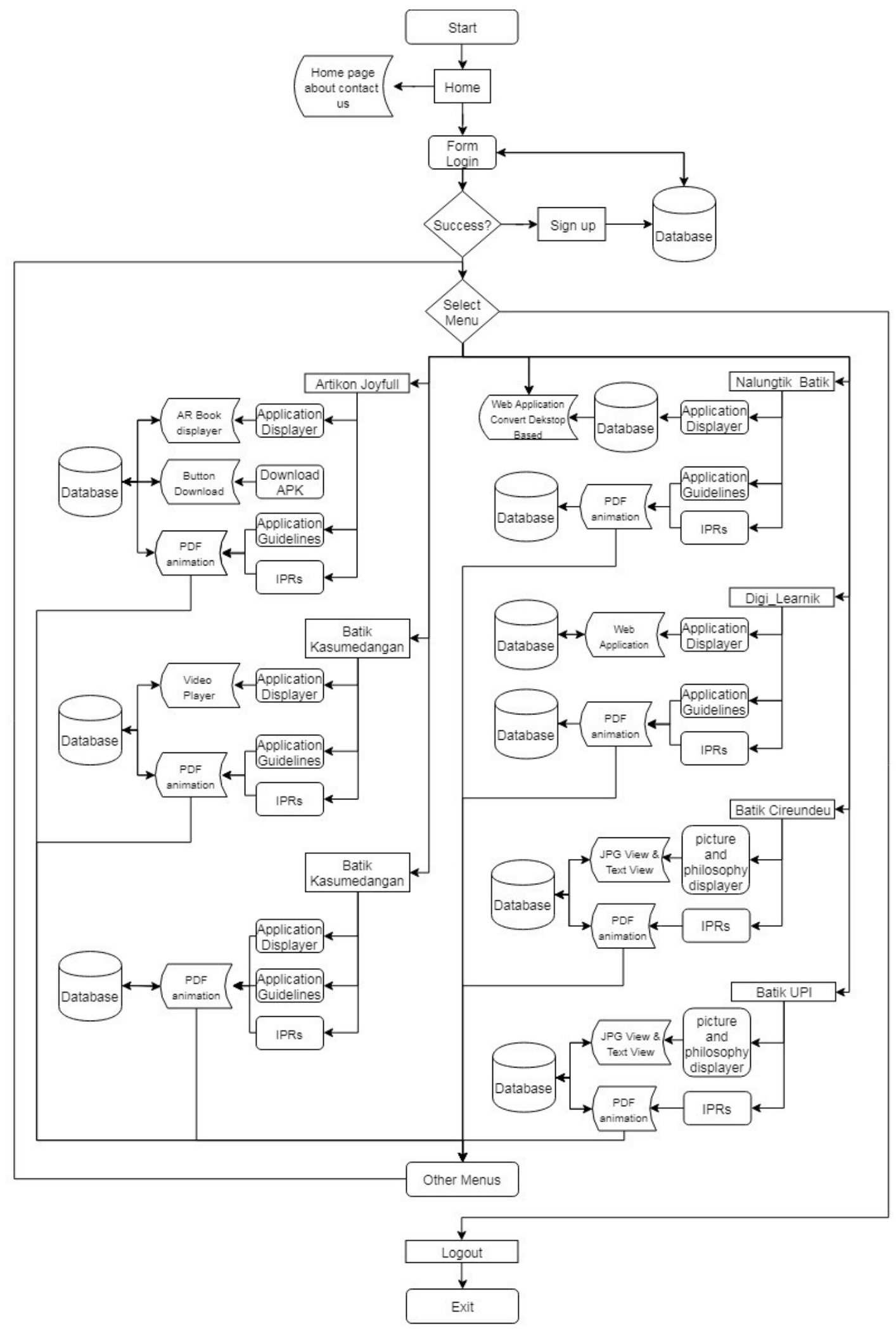

Figure 3. Design of e-botik application display 


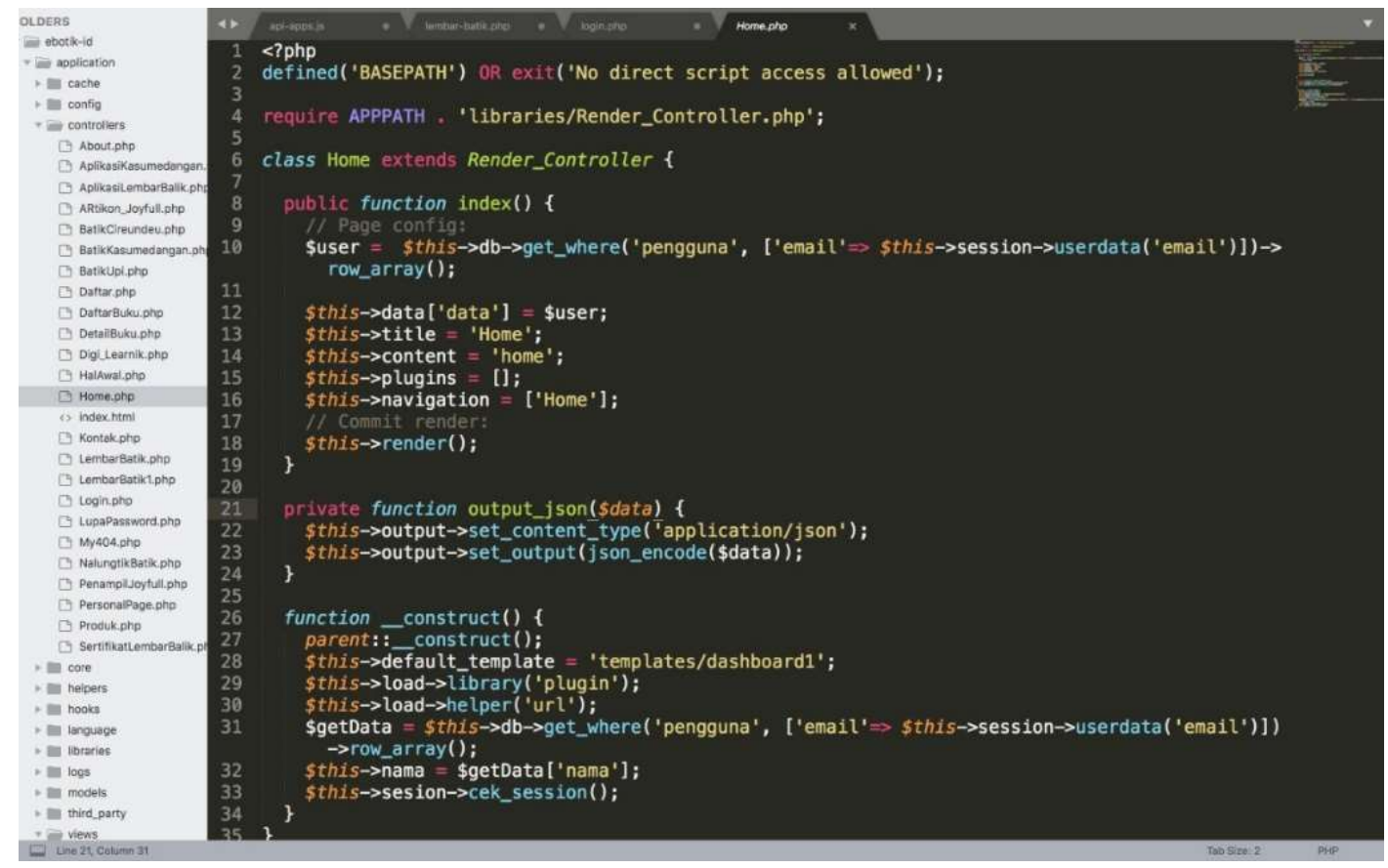

Figure 4. E-botik source code user interface design

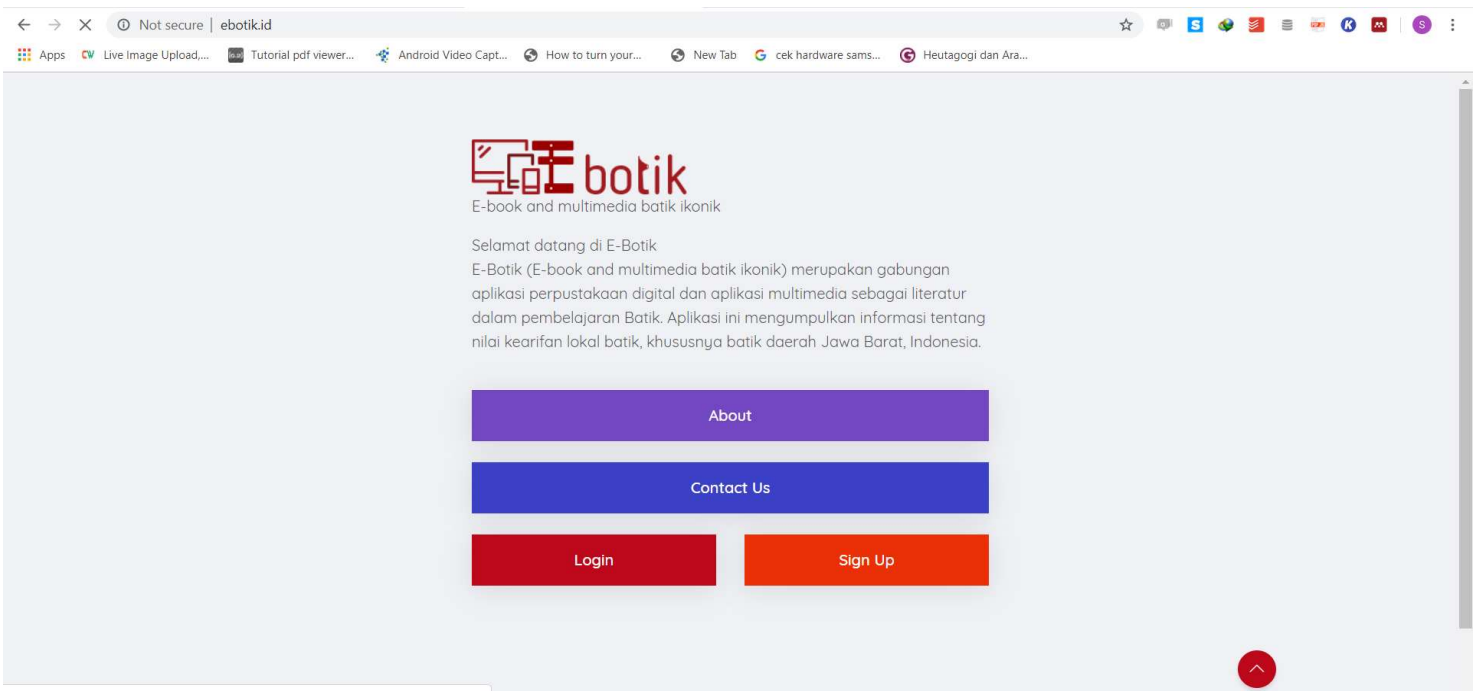

Figure 5. E-botik main menu user interface displav

\subsection{Database}

The database designed for e-botik application is related to the users. The database basically aims to give access to users when using the application. The database was made using premium Navicat application, the process of database development can be seen in Figure 6.

\subsection{API}

The API used as a data connector between previously designed applications and e-botik so that data can be displayed on e-botik. The process of API source code design is presented in Figure 7. 


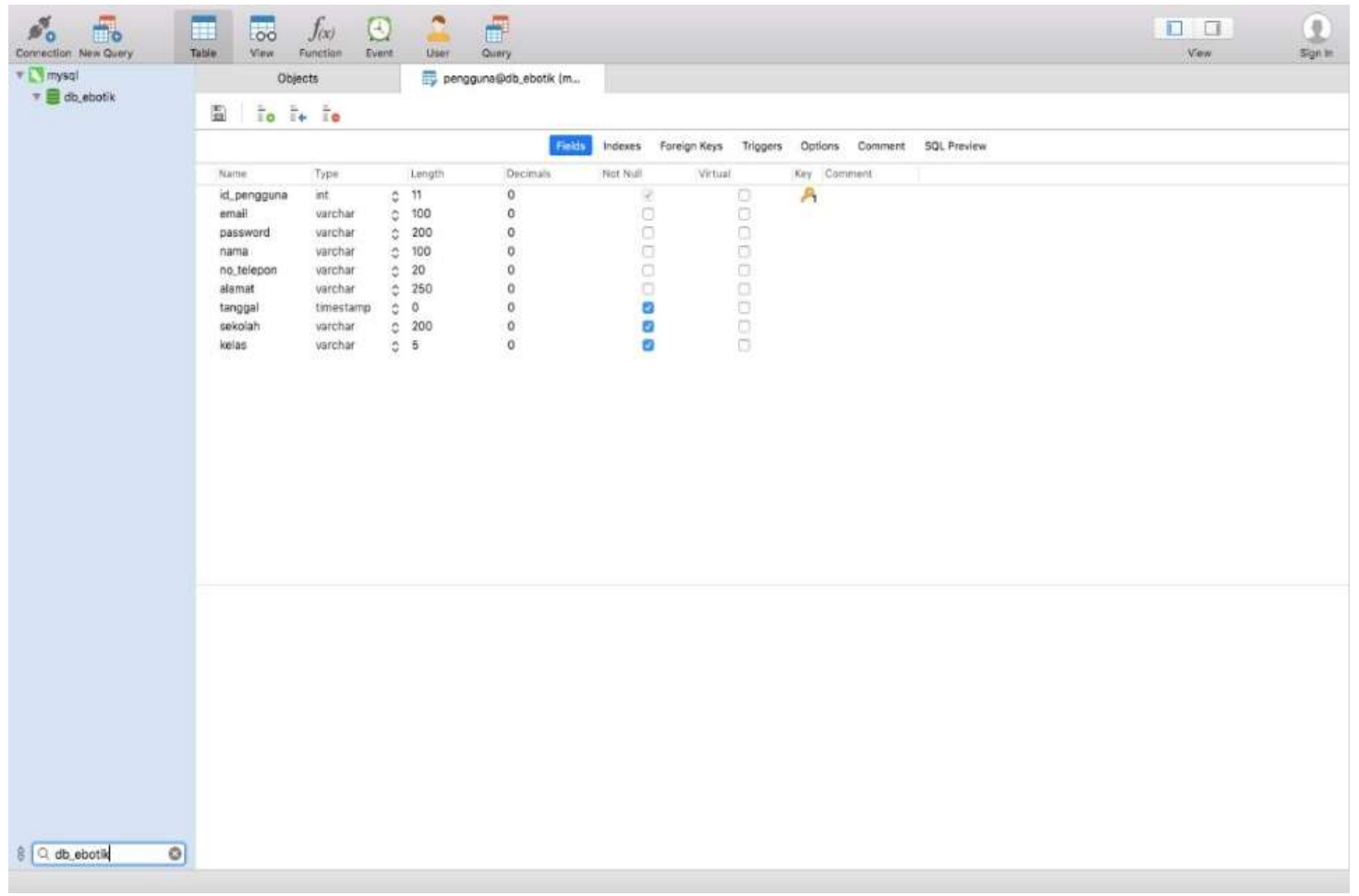

Figure 6. E-botik database design process

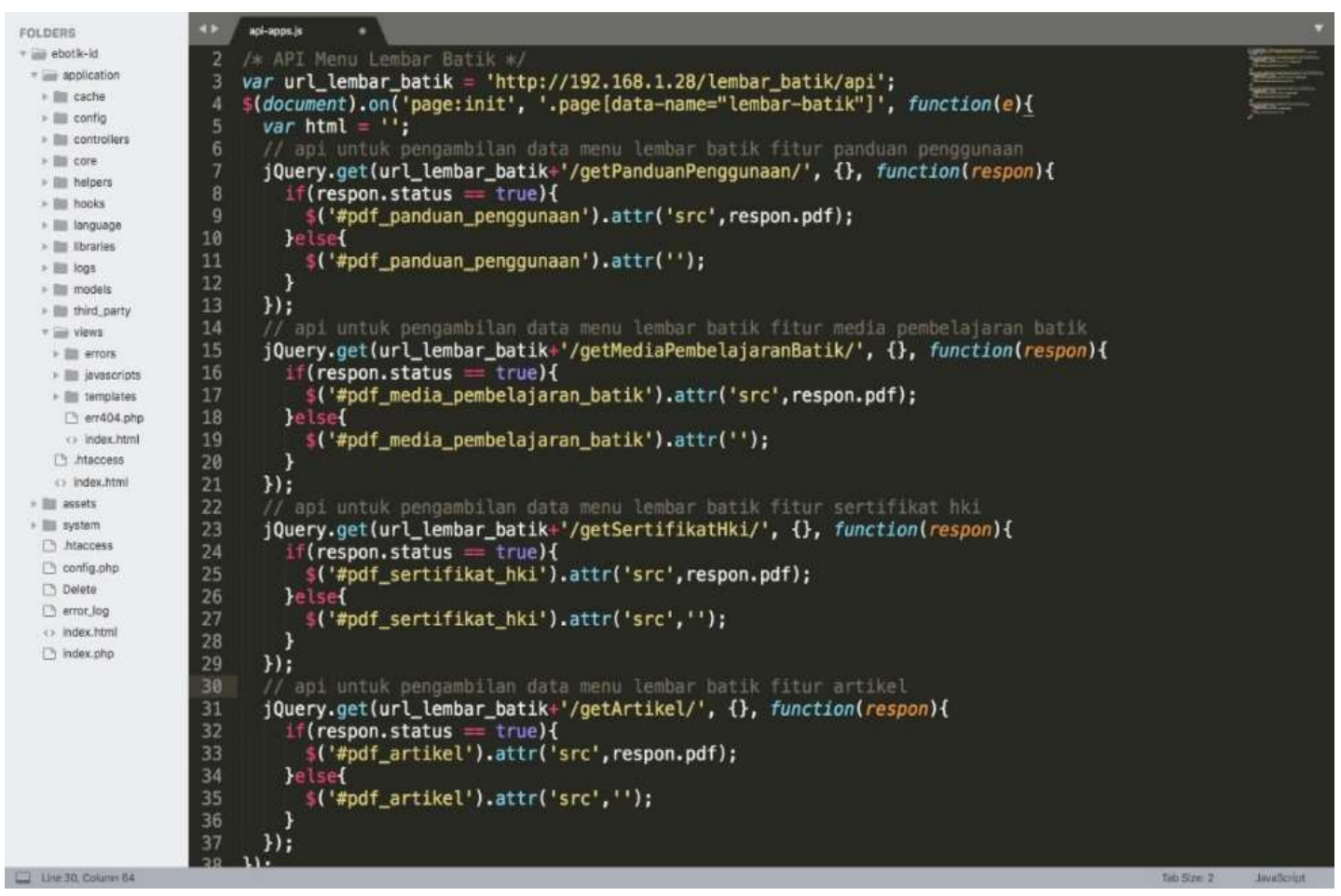

Figure 7. E-botik API source code design process 


\subsection{Testing}

\subsubsection{Whitebox testing}

Whitebox testing is a test case using procedural design control structure. The testing was based on the observation towards detailed procedure so that logical path of the software is tested by providing a test case performing a complication of different conditions or specific repetitions (Nidhra \& Dondeti, 2012). It has been found that through whitebox testing to the application developed, there was no error.

\subsubsection{Blackbox testing}

Blackblox testing is applicable for software interface. The main purpose of this test case is to show the whether the application functions well or not. It is to identify whether the data input runs well and whether the information is saved properly. This type of test focuses on the functionality of the software so that the input is entirely using all the required functions for a certain program (Nidhra \& Dondeti, 2012).

\subsection{E-botik application to support learning batik using a heutagogical approach}

E-botik application which has been designed in the multiplatform setting can be used in learning batik through the heutagogical approach. Some of the features integratedly developed support students to look for a variety of resources which are interesting, friendly, and self-determined.

E-botik application as a multiplatform learning medium consists of several media integrated in a digital platform applicable for learning batik in vocational high schools. The first category of e-botik is two dimensional (non-digital) which is lembar balik batik media (see Figure 8), motif batik Cireundeu (Figure 9), and Motif Batik Universitas Pendidikan Indonesia/ UPI (see Figure 10).

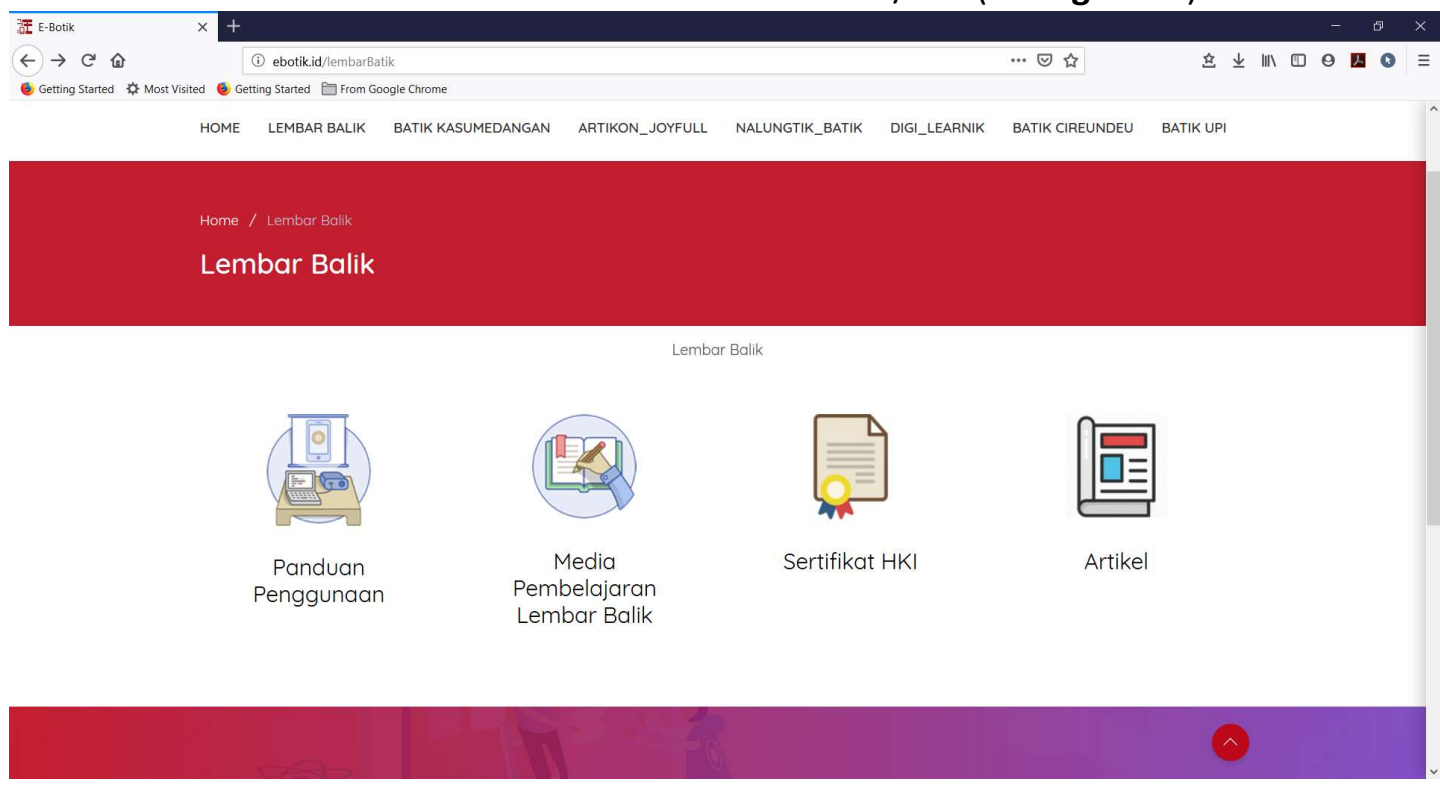

Figure 8. Lembar balik batik application user interface 

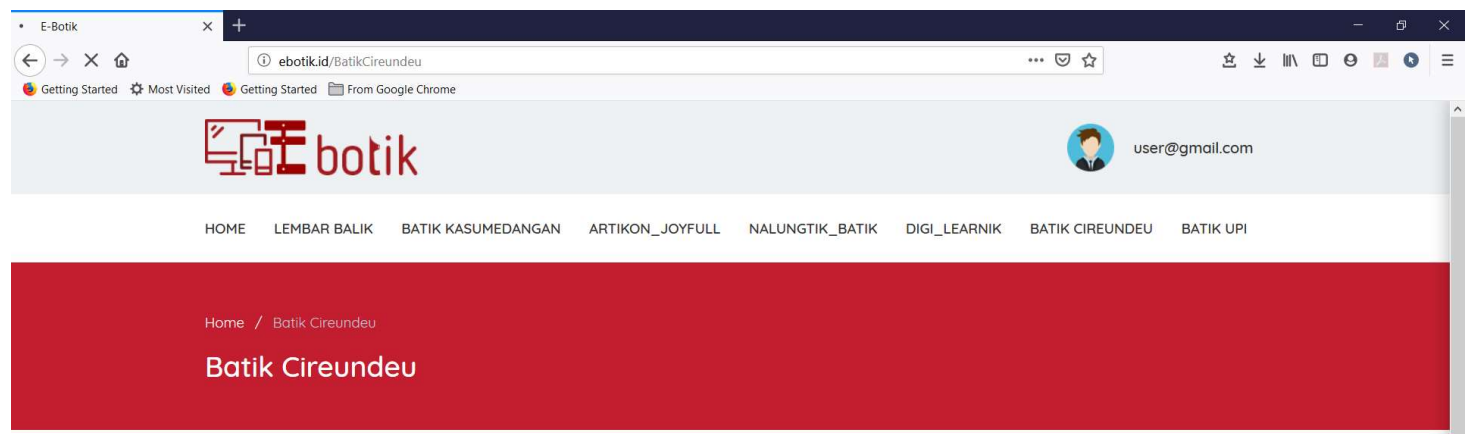

Batik Cireundeu

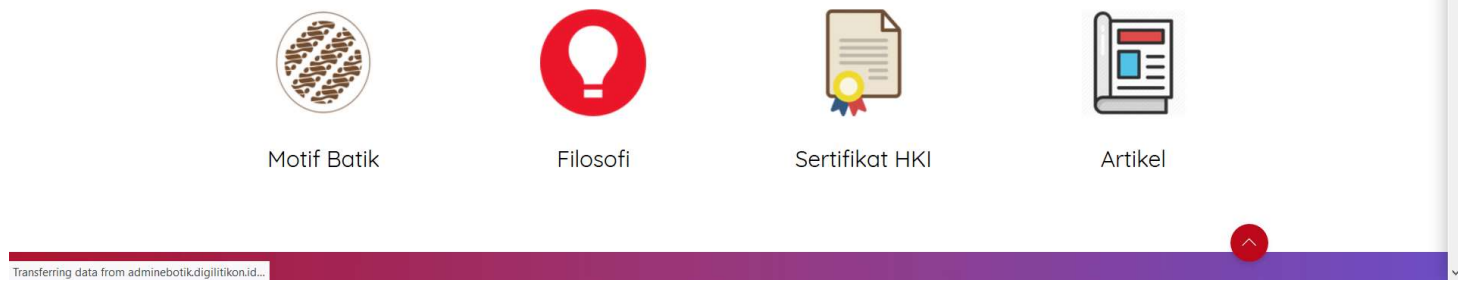

Figure 9. Motif Batik Cireundeu application user interface display on E-Botik display on E-Botik

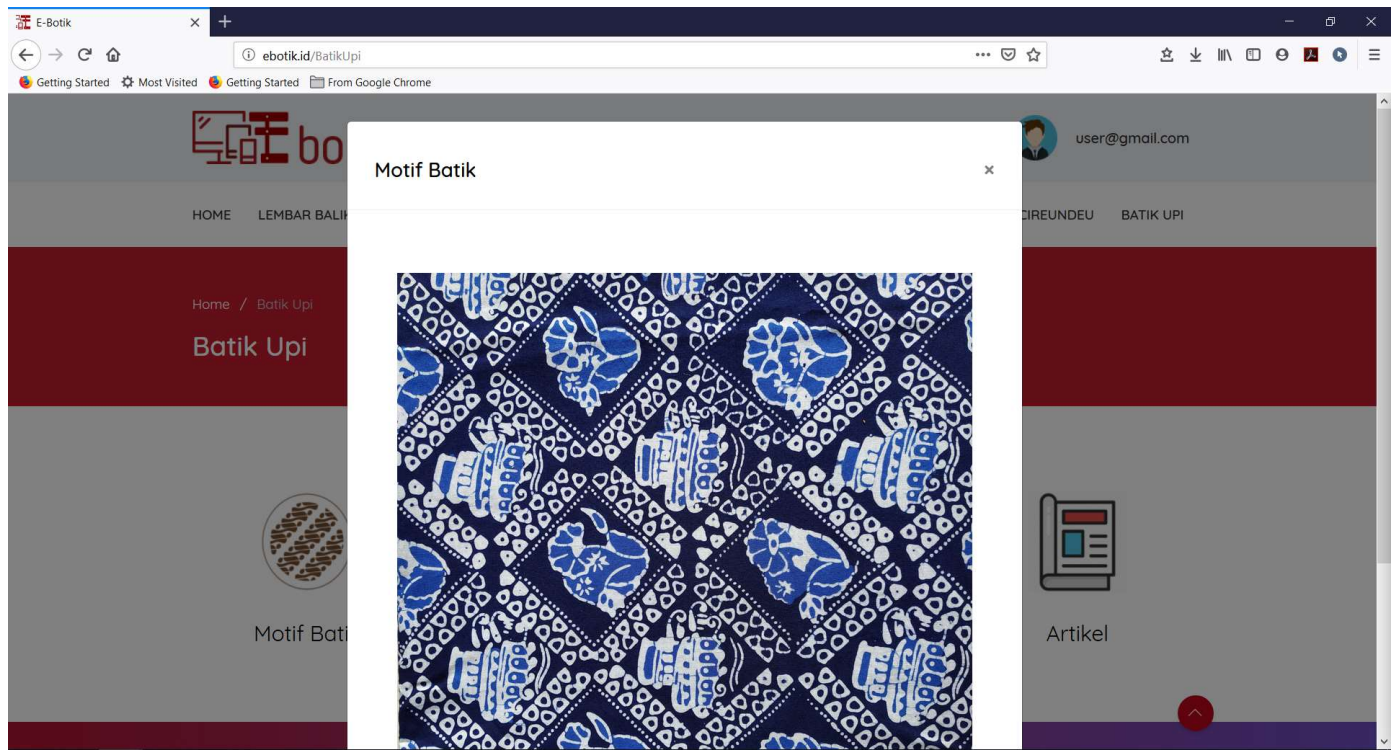

Figure 10. Motif Batik UPI application user interface display on E-Botik

Figures 8, 9, and 10 show the e-batik application based on the two dimensional or non-digital applications. Each of the applications contains such information as guidance, contents of batik and its philosophical meanings, patterns, certification of copyrights acquired, and scientific articles made based on each of the batik explained. Those components tell the students that batik is not only about its patterns, it can be something legalized in terms of its copyrights and its discussion can even be published in internationally reputable journals. This learning model is in line with local wisdom - based learning which is a part of character education and the development of the national identity (Yang, 2016; Burns, 2015). 
The next applications integrated to e-botik are digital ones and based on Android namely Augmented Reality Batik Ikonik (Artikon_Jofrul) (see Figure 11), movie player - based media namely Video Kasumedangan Batik (see Figure
12), a desktop-based application namely Nalungtik Batik (see Figure 13), and a webbased application namely Digital Learning Batik Ikonik (Digi_Learnik) (see Figure 14).

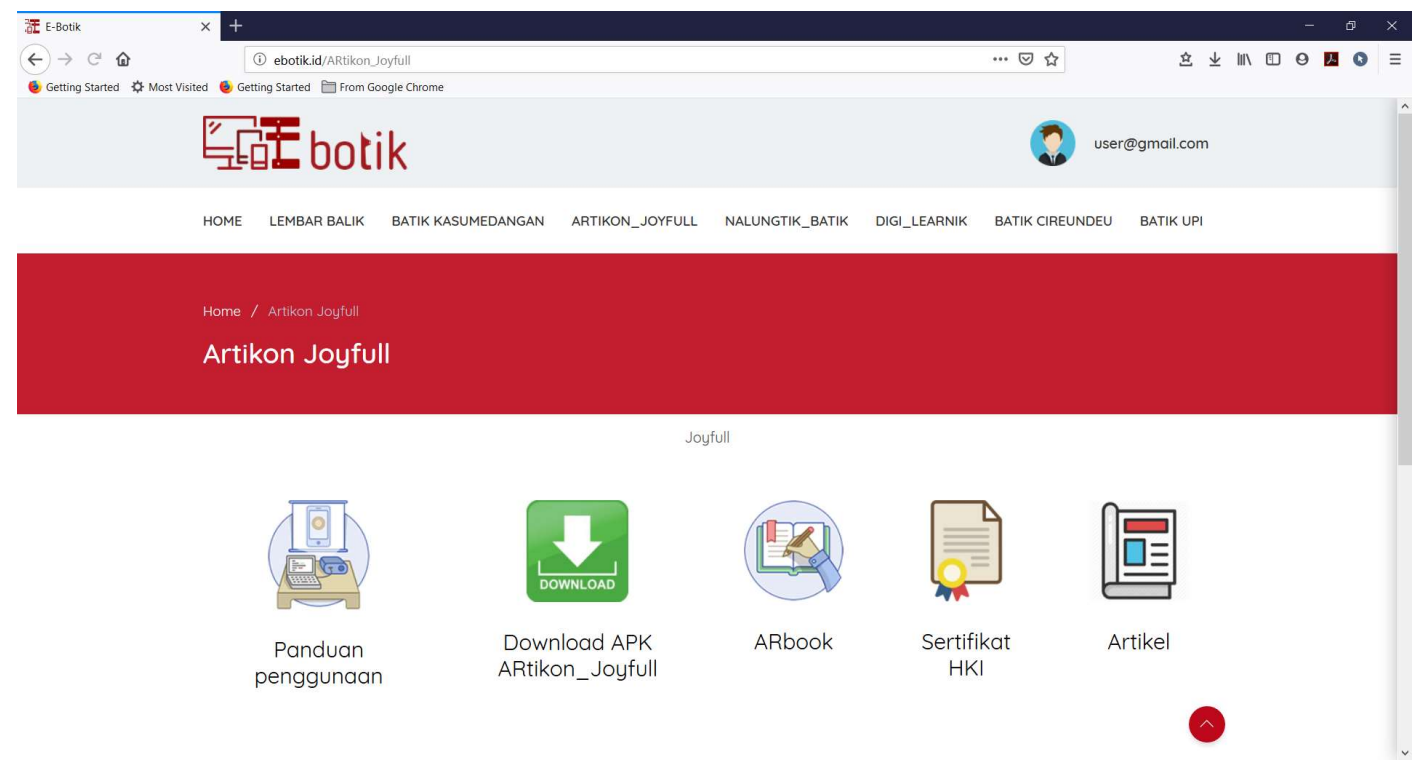

Figure 11. Artikon_Joyful application user interface display on E-Botik

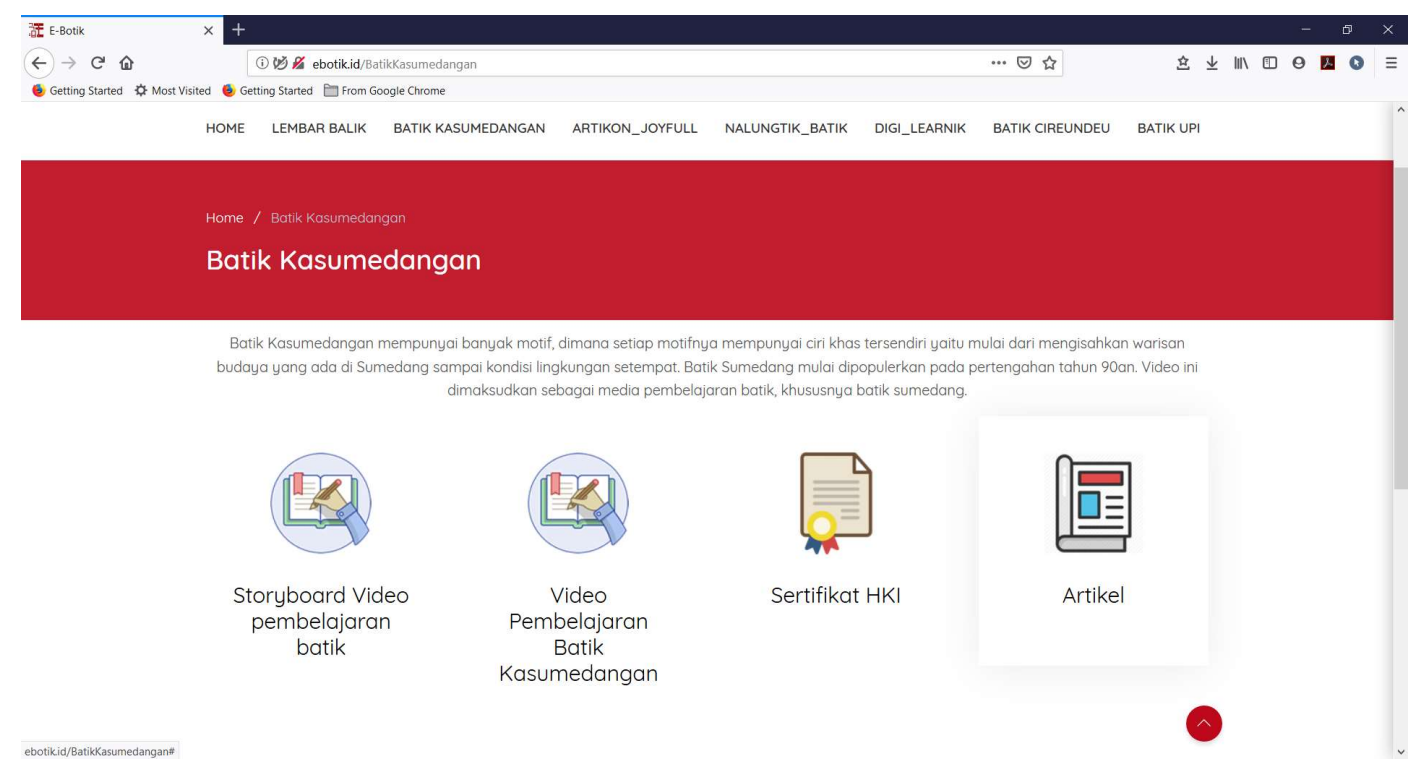

Figure 12. Video Batik Kasumedangan application user interface display on E-Botik 


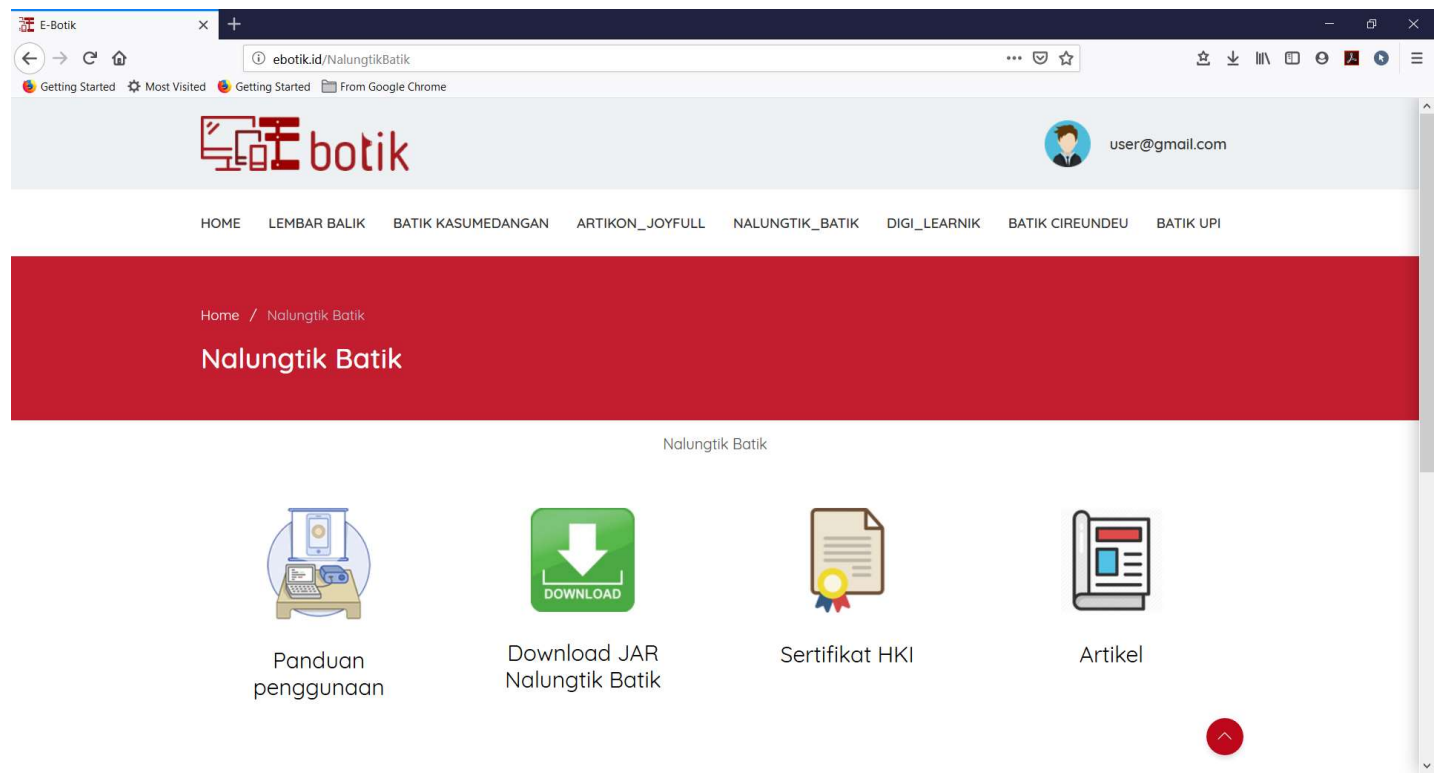

Figure 13. Nalungtik Batik application user interface display on E-Botik

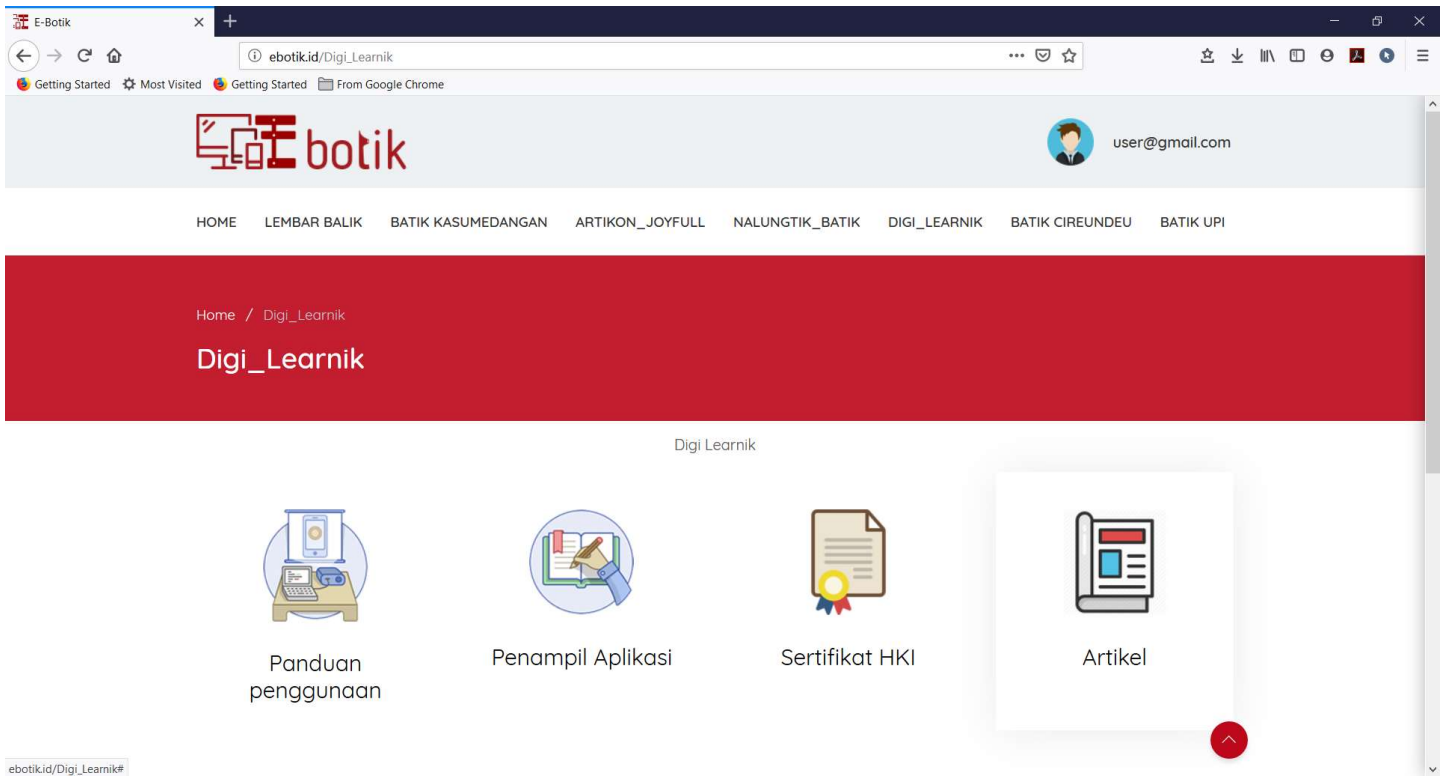

Figure 14. Digi_Learnik application user interface display on E-Botik

Figures 11, 12, 13, and 14 present digital batik learning media designed to give students easier and more interesting ways to learn batik. Multiplatform learning utilizing the digital technology has a positive impact in the contexts of digital compentence development, self-concept, and ICT interest enhancement (Zylka et al., 2015). This leads to meaningful learning (Inayat et al., 2013), mindfulness and contemplative learning (Damico \& Krutka,
2018), and enables students to analyze the themes in accordance with their needs (Painter et al., 2018).

The results of this study showed that technology integration is one of the aspects of maintaining good quality of education, particularly vocational education which should promote comfort for all students, both those with special needs or ones without them 
(Maknun et al., 2019). It is expected that tehcnology integration is a great help of a transparent and objective evalulation so that student performance can be assessed well as it has been proven that such kind of assessment or evaluation (one of which is by using Fuzzy Logic) is a crucial component in education (Amelia et al., 2019). In short, it has to be well understood that both physical and nonphysical aspects play an important role of having good quality of education in general or in vocational schools. It has been identified that having an architectural design which with sun exposure is a good contribution to the vocational high school education (Paramita et al., 2016).

\section{CONCLUSION}

The multiplatform-based batik learning application development in the context of heutagogical approach is becoming a challenge as well as an opportunity in accommodating the development of curriculum based on local wisdom and digital technology. Every attempt to develop curriculum relevant to that of technology basically helps students to learn more deeply, more independently, and in a more fun and interesting way in accordance with their needs. E-botik, the multiplatformbased application designed, is in line with this kind of needs since students have free access to choose the types of learning media they are interested and comfortable with. This way, learning is getting more student-centered.

\section{ACKNOWLEDGMENT}

The Ministry of Research, Technology, and Higher Education of the Republic of Indonesia (KEMENRISTEK DIKTI) is properly acknowledged for funding the research.

\section{REFERENCES}

Abraham, R. R., \& Komattil, R. (2017). Heutagogic approach to developing capable learners. Medical Teacher, 39(3), 295-299.

Adinugroho, T. Y., Reina., \& Gautama, J. B. (2015). Review of multi-platform mobile application development using web view: learning management system on mobile platform. Procedia Computer Science, 59, 291-297.

Amelia, N., Abdullah, A. G., \& Mulyadi, Y. (2019). Meta-analysis of Student Performance Assessment Using Fuzzy Logic. Indonesian Journal of Science and Technology, 4(1), 7488.

Ataie, F., Shah, A., \& Ali, N. I. (2018). Integration social media technology and ethical collaborative learning. International Journal of Engineering and Technology(UAE), 7(2), 12-15.

Blaschke, L. M. (2012). Heutagogy and Lifelong Learning: A review. IRRODL: International Review of Research in Open and Distance Learning, 13(1), 56-71.

Blaschke, L. M. (2014). Using social media to engage and develop the online learner in selfdetermined learning. Research in Learning Technology, 22(1063519).

Brooman, S., Darwent, S., \& Pimor, A. (2015). The student voice in higher education curriculum design: is there value in listening? Innovations in Education and Teaching International, 52(6), 663-674.

Burns, H. L. (2015). Transformative sustainability pedagogy: Learning from ecological systems and indigenous wisdom. Journal of Transformative Education, 133, 259-276. 
59 | Indonesian Journal of Science \& Technology, Volume 5 Issue 1, January 2020 Hal 45-61

Canning, N., \& Callan, S. (2010). Heutagogy: Spirals of reflection to empower learners in higher education. Reflective Practice, 11(1), 71-82.

Chow, C. Y., Kumar, K. N., Showman, K. A., \& Vincent, J. (2011). Application programming interface for identifying, downloading and installing applicable software updates. Google Patents.

Damico, N., \& Krutka, D. G. (2018). Social media diaries and fasts: Educating for digital mindfulness with pre-service teachers. Teaching and Teacher Education, 73, 109-119.

Donovan, J. J., \& Edition, I. S. (1972). Systems programming (Vol. 3). McGraw-Hill New York.

Forsström, S. E. (2019). Role of teachers in students' mathematics learning processes based on robotics integration. Learning, Culture and Social Interaction, 378-389.

Gani, A. G. (2018). Analisis sistem informasi pengelolaan data alumni berbasis codeigniter PHP framework. Jurnal Sistem Informasi Universitas Suryadarma, 5(2).

Green, R. D., \& Schlairet, M. C. (2017). Moving toward heutagogical learning: Illuminating undergraduate nursing students' experiences in a flipped classroom. Nurse Education Today, 49, 122-128.

Guccione, S., Levi, D., \& Sundararajan, P. (1999). JBits: A Java-based interface for reconfigurable computing. 2nd Annual Military and Aerospace Applications of Programmable Devices and Technologies Conference (MAPLD), 261, 1-9.

Halsall, J. P., Powell, J. L., \& Snowden, M. (2016). Determined learning approach: Implications of heutagogy society based learning. Cogent Social Sciences, 2(1), 1-11.

Hase, S. (2011). Learner defined curriculum: Heutagogy and action learning in vocational training. Southern Institute of Technology Journal of Applied Research, 1-10.

Hase, S. (2012). Heutagogy and e-learning in the workplace: Some challenges and opportunities. Journal of Applied Research in Workplace E-Learning, 1(1), 8.

Hase, S., \& Kenyon, C. (2001a). Moving from andragogy to heutagogy: Implications for VET moving from andragogy to heutagogy in vocational education. Australian Vocational Education and Training Research Association (AVETRA).

Hase, S., \& Kenyon, C. (2001b). Moving from andragogy to heutagogy: Implications for VET moving from andragogy to heutagogy in vocational education. Australian Vocational Education and Training Research Association (AVETRA), 28-30.

Hase, S., \& Kenyon, C. (2003). Heutagogy and developing capable people and capable workplaces: Strategies for dealing with complexity. Proceedings of The Changing Face of Work and Learning Conference, 1-7.

Hase, S., \& Kenyon, C. (2007). Heutagogy: A child of complexity theory. An International Journal of Complexity and Education, 4(1), 111-118.

Haworth, R. (2016). Personal learning environments: A solution for self-directed learners. TechTrends, 60(4), 359-364.

Hustinawati, H., Kurnia Himawan, A., \& Latifah, L. (2014). Performance analysis framework codeigniter and CakePHP in website creation. International Journal of Computer Applications, 94(20), 6-11.

Hyun, E. (2006). Transforming instruction into pedagogy through curriculum negotiation. Journal of Curriculum and Pedagogy, 3(1), 136-164. 
Inayat, I., Amin, R. U., Inayat, Z., \& Salim, S. S. (2013). Effects of collaborative web based Vocational Education and Training (VET) on learning outcomes. Computers and Education, 68, 153-166.

Law, W. W. (2014). Understanding China's curriculum reform for the 21st century. Journal of Curriculum Studies, 46(3), 332-360.

Maknun, J., Barliana, M. S., \& Cahyani, D. (2019). A Design Model of Special Vocational High School for Children with Visual Impairment. Indonesian Journal of Science and Technology, 4(2), 158-170.

Narayan, V., \& Herrington, J. (2014). Towards a theoretical mobile heutagogy framework. SCILITE 2014: Rhetoric and Reality, 150-160.

Nidhra, S., \& Dondeti, J. (2012). Black box and white box testing techniques-a literature review. International Journal of Embedded Systems and Applications (IJESA), 2(2), 2950.

Paik, S. (2015). Teachers' attention to curriculum materials and students contexts: The case of Korean middle school teachers. The Asia-Pacific Education Researcher, 24(1), 235246.

Painter, J., Kristiansen, S., \& Schäfer, M. S. (2018). How 'Digital-born' media cover climate change in comparison to legacy media: A case study of the COP 21 summit in Paris. Global Environmental Change, 48, 1-10.

Paramita, B., Kamilia, I., Nurhidayat, M. I., \& Ocktaviyane, R. (2016). Optimization of Design and Planing VHS Building Using Chronolux. Indonesian Journal of Science and Technology, 1(2), 170-184.

Pereira, D., Gomes, P., Sá, C., Costa, O., Nogueira Reis, Z. S., Mattos, S., Cruz-Correia, R., Coimbra, M. T. (2017). IS4Learning-A multiplatform simulation technology to teach and evaluate auscultation skills. Health Professionals' Education in the Age of Clinical Information Systems, Mobile Computing and Social Networks, 401-420.

Prokofyeva, N., \& Boltunova, V. (2017). Analysis and practical application of PHP frameworks in development of web information systems. Procedia Computer Science, 104, 51-56.

Rieger, C., \& Majchrzak, T. A. (2019). Towards the definitive evaluation framework for crossplatform app development approaches. Journal of Systems and Software, 153, 175199.

Rodriguez-Gil, L., Garcia-Zubia, J., Orduna, P., \& Lopez-De-Ipina, D. (2017). Towards new multiplatform hybrid online laboratory models. IEEE Transactions on Learning Technologies, 10(3), 318-330.

Salam, M., Awang Iskandar, D. N., Ibrahim, D. H. A., \& Farooq, M. S. (2019). Technology integration in service-learning pedagogy: A holistic framework. Telematics and Informatics, 38, 257-273.

Sangiorgi, U. B. (2014). Electronic sketching on a multi-platform context: A pilot study with developers. International Journal of Human Computer Studies, 72(1), 45-52.

Schüler, A. (2019). The integration of information in a digital, multi-modal learning environment. Learning and Instruction, 59, 76-87.

Van Thiel, L. (2018). Professional learning design framework: Supporting technology 
61 | Indonesian Journal of Science \& Technology, Volume 5 Issue 1, January 2020 Hal 45-61

integration in Alberta. Research in Learning Technology, 26(1063519), 1-24.

Vuksanovic, I. P., \& Sudarevic, B. (2011). Use of web application frameworks in the development of small applications. 2011 Proceedings of the 34th International Convention MIPRO, 458-462.

Widiaty, I., Achdiani, Y., Kuntadi, I., Mubaroq, S. R., \& Zakaria, D. (2018). The 3D digital storytelling media on batik learning in vocational high schools. IOP Conference Series: Materials Science and Engineering, 306(1), 012062.

Widiaty, I., Riza, L. S., Abdullah, A. G., \& Mubaroq, S. R. (2018). Application of desktop-based batik information system. IOP Conference Series: Materials Science and Engineering, 288(1), 012086.

Widiaty, I., Riza, L. S., Ana, A., Abdullah, A. G., Mubaroq, S. R., \& Abdullah, M. (2018). Designing a content setting application on YouTube in learning batik in a vocational school. IOP Conference Series: Materials Science and Engineering, 434(229), 012307.

Widiaty, I., Riza, L. S., \& Danuwijaya, A. A., Hurriyati, R., \& Mubaroq, S. R. (2017). Mobilebased augmented reality for learning 3-dimensional spatial batik-based objects. Journal of Engineering Science and Technology, 12, 12-22.

Widiaty, I., Riza, L. S., Somantri, L., Abdullah, A. G., Ana, Mubaroq, S. R., \& Abdullah, C. U. (2018). Geographic information system of batik Jawa Barat: Cultural and industrial mapping for supporting the development of curriculum in vocational high schools. Journal of Engineering Science and Technology, 13(7), 1979-1991.

Widiaty, I., Yustiawan, I., Wibisono, Y., Abdullah, A. G., Abdullah, C. U., \& Riza, L. S. (2018). Implementation of markerless augmented reality method to visualise philosophy of batik based on Android. Pertanika Journal of Science and Technology, 26(3), 13831400.

Yang, S. (2016). Exploring wisdom in the Confucian tradition: Wisdom as manifested by Fan Zhongyan. New Ideas in Psychology, 41, 1-7.

Zylka, J., Christoph, G., Kroehne, U., Hartig, J., \& Goldhammer, F. (2015). Moving beyond cognitive elements of ICT literacy: First evidence on the structure of ICT engagement. Computers in Human Behavior, 53, 149-160. 